\title{
Unsedated transnasal endoscopy: A Canadian experience in daily practice
}

\author{
Sarah Cho MB BS, Naveen Arya MD, Katherine Swan MD, Maria Cirocco MA, \\ Gabor Kandel MD, Paul Kortan MD, Norman Marcon MD
}

S Cho, N Arya, K Swan, et al. Unsedated transnasal endoscopy: A Canadian experience in daily practice. Can J Gastroenterol 2008;22(3):243-246.

BACKGROUND: Esophagogastroduodenoscopy (EGD) is the most frequently performed diagnostic procedure for upper gastrointestinal disorders. The procedure is routinely performed under conscious sedation in North America. A significant proportion of morbidity and mortality associated with EGD is related to hypoxia due to conscious sedation. The use of sedation is also associated with an increase in cost, loss of work on the day of endoscopy and the need for the patient to be accompanied home after the procedure. Transnasal endoscopy has advantages such as no sedation and less patient monitoring, nursing time and expenses than conventional per oral EGD. OBJECTIVES: To assess the feasibility and acceptability of unsedated transnasal EGD in daily practice.

METHODS: Patients due to undergo EGD were given a choice of either unsedated transnasal EGD or per oral EGD with sedation. Patients who chose unsedated transnasal EGD had the procedure performed in the office by a senior gastroenterologist with experience in transnasal EGD. All procedures were performed using a small-calibre esophagogastroduodenoscope. All patients were surveyed using a patient satisfaction questionnaire, and were asked to give specific scores in terms of choking sensation, sore throat, nasal discomfort and abdominal discomfort. All variables were assessed by scores between 0 and 10, with 10 indicating the most severe degree of each variable. Any complications were also recorded.

RESULTS: Between March 2002 and August 2003, 231 patients underwent transnasal EGD. The median age of the patients was 57 years (range 15 to 87 years). Complete examinations were possible in $98 \%$ of patients. Patients reported a high degree of acceptability (mean score 6.6, range 1 to 10) and low degrees of choking sensation (mean 1.8, range 0 to 10 ), nasal discomfort (mean 1.7, range 0 to 10 ), sore throat (mean 0.8 , range 0 to 9 ) and abdominal discomfort (mean 1.1 , range 0 to 10 ). The only complications reported by the patients were epistaxis $(n=2,0.9 \%)$ and sinusitis $(n=1,0.4 \%)$. Some patients also reported transient light-headedness $(n=12,5 \%)$ and mucous discharge $(n=2,0.9 \%)$. When asked, 185 patients $(88 \%)$ stated that they were willing to undergo the same procedure in the future if medically indicated. Of the 84 patients who had conventional EGD under conscious sedation in the past, 52 patients $(62 \%)$ preferred transnasal EGD without sedation.

CONCLUSIONS: Transnasal EGD is generally well tolerated, feasible and safe. It can be performed with topical anesthesia in an outpatient setting. The low complication rate, high patient satisfaction and potential cost savings make transnasal endoscopy an attractive alternative to conventional EGD to screen patients for upper gastrointestinal tract diseases.

Key Words: EGD; Sedation; Transnasal endoscopy

\section{L'endoscopie transnasale sans sédation : Une expérience canadienne dans la pratique quotidienne}

HISTORIQUE : L'œsophagogastroduodénoscopie (OGD) est l'interven-
tion diagnostique la plus pratiquée pour les troubles œesogastroduodénaux.
Elle est couramment exécutée sous sédation consciente en Amérique du
Nord. Une forte proportion de la morbidité et de la mortalité associées à
l'OGD est reliée à l'hypoxie attribuable à la sédation consciente. La sédation
est également liée à une augmentation des coûts, à l'absence du travail le jour
de l'endoscopie et à la nécessité que le patient se fasse accompagner à la mai-
son après l'intervention. L'endoscopie transnasale comporte des avantages,
tels que l'absence de sédation et une diminution de la surveillance du
patient, du temps des infirmières et des dépenses par rapport à l'OGD par
voie orale classique. OBJECTIFS : Évaluer la faisabilité et l'acceptabilité de l'OGD transnasale sans sédation dans la pratique quotidienne.

MÉTHODOLOGIE : Les patients devant subir une OGD ont eu le choix entre une OGD transnasale sans sédation et une OGD par voie orale sous sédation. Les patients qui choisissaient l'OGD transnasale sans sédation subissaient l'intervention en cabinet par un gastroentérologue principal expérimenté dans les OGD transnasales. Toutes les interventions étaient effectuées à l'aide d'un œsophagogastroduodénoscope de petit calibre. Tous les patients ont été interrogés à l'aide d'un questionnaire sur la satisfaction des patients et ont été invités à attribuer des indices précis sur la sensation d'étouffement, le mal de gorge, le malaise nasal et le malaise abdominal. Toutes les variables ont été évaluées au moyen d'indices de 0 à 10, 10 correspondant au degré le plus grave de chaque variable. Les complications ont également été enregistrées.

RÉSULTATS : Entre mars 2002 et août 2003, 231 patients ont subi une OGD transnasale. Les patients avaient un âge médian de 57 ans (fourchette de 15 à 87 ans). Il a été possible de procéder à un examen complet chez $98 \%$ des patients. Les patients ont déclaré un fort degré d'acceptabilité (indice moyen de 6,6, fourchette de 1 à 10) et un faible degré de sensation d'étouffement (moyenne 1,8, fourchette de 0 à 10 ), de malaise nasal (moyenne 1,7, fourchette de 0 à 10), de mal de gorge (moyenne 0,8 , fourchette de 0 à 9 ) et de malaise abdominal (moyenne 11, fourchette de 0 à 10). Les seules complications qu'ont déclarées les patients sont une épistaxis ( $\mathrm{n}=2,0,9 \%$ ) et une sinusite $(n=1,0,4 \%)$. Certains patients ont également déclaré de légers étourdissements $(n=12,5 \%)$ et un écoulement de mucus ( $n=2,0,9 \%)$. Lorsqu'on leur a posé la question, 185 patients ( $88 \%$ ) ont affirmé qu'ils seraient prêts à subir la même intervention de nouveau si leur état médical l'exigeait. Des 84 patients qui avaient subi une OGD classique sous sédation consciente par le passé, 52 (62\%) ont préféré l'OGD transnasale sans sédation.

CONCLUSIONS : En général, l'OGD transnasale est bien tolérée, faisable et sécuritaire. On peut l'effectuer en consultations externes, au moyen d'une anesthésie topique. Le faible taux de complications, la forte satisfaction des patients et les économies potentielles font de l'endoscopie transnasale une solution de rechange intéressante par rapport à l'OGD classique pour dépister les patients atteints d'une maladie œesogastroduodénale.

The Centre for Therapeutic Endoscopy and Endoscopic Oncology, Division of Gastroenterology, St Michael's Hospital, University of Toronto, Toronto, Ontario

Correspondence: Dr Sarah Cho, Royal North Shore Hospital, Pacific Highway, Sydney NSW 2065, Australia. Telephone 6-129-906-8129, fax 6-129-438-3220, e-mail scho74@hotmail.com

Received for publication September 11, 2007. Accepted October 17, 2007 
$\mathrm{E}_{\mathrm{per}}^{\mathrm{so}}$ phagogastroduodenoscopy (EGD) is the most frequently performed diagnostic procedure for upper gastrointestinal disorders. It is a relatively safe procedure, but complications do occur, with overall morbidity and mortality rates of $0.13 \%$ and $0.004 \%$, respectively $(1)$. The procedure is routinely performed under conscious sedation in North America. Although studies with conventional endoscopes have suggested that EGD with sedation is more comfortable than without sedation $(2,3)$, a significant proportion of morbidity and mortality is related to hypoxia due to conscious sedation, with elderly patients and individuals with underlying cardiopulmonary disease at a greater risk (4-6). In addition, the use of sedation is associated with an increase in costs due to the greater need for patient monitoring, experienced nursing staff, recovery rooms and drugs (7). It also results in an increased loss of work time on the day of endoscopy (8) and the need for the patient to be accompanied home after the procedure.

In Asia, Latin America and in some of the European countries, unsedated EGD is the routine practice $(9,10)$. With the development of small-calibre endoscopes, several studies have explored the feasibility of unsedated EGD with ultra-thin endoscopes via both per oral and transnasal routes. The transnasal route for upper endoscopy causes less gagging and is better tolerated overall than the per oral route. Despite the literature indicating that transnasal endoscopy has many advantages over sedated per oral EGD, it is not often used in Canadian gastroenterology. This may be due to concern over patient selection in the reported trials and the expectations that Canadian patients have to receive sedation when they undergo EGD. We report a Canadian single-centre experience of unsedated transnasal EGD and a review of the literature. The objective of the present study was to assess the feasibility and acceptability of unsedated transnasal EGD in daily practice.

\section{METHODS}

Patients due to undergo EGD were given a choice of undergoing unsedated transnasal EGD within the same month or per oral EGD with sedation in six to nine months. Patients who chose unsedated transnasal EGD had the procedure performed in the office by a senior gastroenterologist with experience in transnasal EGD.

All procedures were performed using a Pentax small-calibre esophagogastroduodenoscope (Pentax FG 16V, Pentax Precision Instrument Co, USA). It had an insertion tube outer diameter of $5.3 \mathrm{~mm}$ and a $2 \mathrm{~mm}$ biopsy channel. Topical anesthesia was induced in the nasal cavity by spraying a solution of $5 \%$ lidocaine. No sedation was used. A nurse was present to assist in biopsies and oral suction. The endoscope was inserted through the nose and the upper esophageal sphincter under direct vision, and the esophagus, stomach and duodenum down to the second part were examined as usual. Biopsies were performed when clinically indicated.

All patients were contacted within seven days by a research assistant who was not present at the time of the procedures, and were surveyed using a patient satisfaction questionnaire. They were asked whether they would accept the same procedure in the future if necessary. Patients who had undergone conventional EGD with conscious sedation in the past were asked which procedure they preferred. All patients were also asked to give specific scores in terms of choking sensation, sore throat, nasal discomfort and abdominal discomfort. All variables were assessed by scores between 0 and 10 , with 10 being the most
TABLE 1

\begin{tabular}{lc}
$\begin{array}{l}\text { Patient demographics and indications for transnasal } \\
\text { esophagogastroduodenoscopy }\end{array}$ \\
\hline Variable & Patients \\
\hline Patients, $n$ & 231 \\
Age, years, median (range) & $57(15-87)$ \\
Male:Female & $131: 100$ \\
Indication, $n(\%)$ & \\
Dyspepsia & $115(49.8)$ \\
Heartburn & $52(22.5)$ \\
Anemia & $36(15.6)$ \\
Dysphagia & $10(4.3)$ \\
Gastric cancer screening & $5(2.2)$ \\
Nausea & $4(1.7)$ \\
Weight loss & $3(1.3)$ \\
Radiology anomaly & $3(1.3)$ \\
Postsurgery or postpolypectomy & $3(1.3)$ \\
\hline
\end{tabular}

severe degree of choking, sore throat, nasal discomfort and abdominal discomfort. Any complications were also recorded.

\section{RESULTS}

Between March 2002 and August 2003, 231 patients underwent transnasal EGD. The median age of the patients was 57 years (range 15 to 87 years) and 100 patients were women. The indications for the procedure were dyspepsia $(n=115)$, reflux symptoms $(n=52)$, anemia $(n=36)$, dysphagia $(n=10)$, family history of gastric cancer $(n=5)$, nausea and vomiting $(n=4)$, weight loss $(n=3)$, radiological abnormality $(n=3)$, postsurgical screening $(n=2)$ and postpolypectomy evaluation $(n=1)$ (Table 1). Eightyseven patients $(38 \%)$ were found to have no abnormalities. However, other abnormalities found in descending frequency included hiatus hernias, esophagitis, Schatzki's rings, pangastritis, antritis, gastric erosions, gastric polyps, nodules, Cameron lesions, peptic ulcer disease, esophageal and gastric cancers, gastric antral vascular ectasia and bezoars.

Transnasal EGD failed in five of the 231 patients (2\%) due to difficulties in intubating the nasal passage. Complete examinations, including the second part of the duodenum and biopsy sampling where indicated, were possible in all other patients once the nasal tract was passed. Patients reported a high degree of acceptability (mean score 6.6, range 1 to 10 ) and low degrees of choking sensation (mean score 1.8 , range 0 to 10 ), nasal discomfort (mean score 1.7 , range 0 to 10 ), sore throat (mean score 0.8 , range 0 to 9 ) and abdominal discomfort (mean score 1.1 , range 0 to 10 ) (Table 2 ). The only complications reported by the patients were epistaxis $(n=2,0.9 \%)$ and sinusitis $(n=1,0.4 \%)$. Some patients also reported transient light-headedness $(n=12,5 \%)$ and mucous discharge $(n=2,0.9 \%)$. When asked, 185 patients $(88 \%)$ stated that they were willing to undergo the same procedure in the future if medically indicated. Of the 84 patients who had conventional EGD under conscious sedation in the past, 52 patients $(62 \%)$ preferred transnasal EGD without sedation.

\section{DISCUSSION}

With the development of small-calibre endoscopes, unsedated transnasal EGD is a potentially cost-effective option in investigating patients with symptoms warranting endoscopic 
examination of the upper gastrointestinal tract. Two studies $(8,11)$ comparing transnasal EGD using a small-calibre endoscope to per oral EGD using a standard endoscope have shown that the transnasal route of intubation for unsedated upper endoscopy is better tolerated overall than the per oral route. Compared with per oral intubation, transnasal intubation is thought to result in less gagging and retching due to the absence of contact between the endoscope and the base of the tongue, thereby reducing the risk of aspiration. The added advantages of transnasal intubation also include the reduced risk of patients biting the tube and the the ability of patients to speak during the procedure, which may reduce their anxiety levels $(12,13)$. In the present study, significant numbers of patients who in the past had conventional EGD with conscious sedation preferred unsedated transnasal EGD with an ultra-thin endoscope (62\%). Furthermore, $88 \%$ of the patients stated that they were willing to undergo the same procedure in the future if medically indicated. These results are consistent with the high level of patient tolerability and acceptability of transnasal EGD in the literature. Dumortier et al (14) reported that 982 of 1033 patients $(95.2 \%)$ who underwent transnasal EGD with $5.3 \mathrm{~mm}$ and $5.9 \mathrm{~mm}$ endoscopes would agree to undergo the procedure again if necessary.

Several studies have compared unsedated transnasal EGD and unsedated per oral EGD using small-calibre endoscopes. Zaman et al (15) suggested from their prospective study that the per oral route may be more preferable with a $5.9 \mathrm{~mm}$ endoscope. However, Preiss et al (13), in their prospective study of 150 patients, found that patients undergoing transnasal EGD with a $5.9 \mathrm{~mm}$ endoscope required less sedation than per oral EGD using the same size endoscope. Some studies suggest that the diameter of the endoscope might play an important role in patient tolerance and in the success of transnasal intubation. In the present study, a $5.3 \mathrm{~mm}$ outer diameter fibre optic endoscope was used, and the failure rate of transnasal EGD due to a narrow nasal tract was only $2 \%$. Craig et al (16), who compared a $5.9 \mathrm{~mm}$ video endoscope to a $5.3 \mathrm{~mm}$ fiberoptic endoscope, found that failure was significantly more frequent with the larger endoscope (19.5\% versus $4.6 \%)$. Similar findings were noted by Dumortier et al (14) ( $16.7 \%$ versus $4.7 \%)$. Some of the other predictive factors for poorly tolerated unsedated endoscopy described in the literature include young age, female sex, high anxiety levels and low body mass index $(12,13)$.

Complications of transnasal EGD are rare. Epistaxis is the most common complication but it is usually mild and resolves spontaneously. Less than $1 \%$ of the patients in the present study had epistaxis. The rate of epistaxis ranges from $0 \%$ to $22.6 \%$ in the literature, and appears to occur more often with a $5.9 \mathrm{~mm}$ video endoscope than with a $5.3 \mathrm{~mm}$ fibre optic endoscope (14-16). Only a single incidence of upper esophageal perforation has been reported (15).

One major issue with transnasal EGD is the decreased ability of physicians using the small-calibre endoscopes to carry out satisfactory examination because of the technical difficulty due to greater flexibility and limited optical capabilities. The development of the small-calibre video endoscopes has provided an improved image compared with the older smallcalibre fibre optic endoscopes, although the resolution is inferior to that of modern high-resolution endoscopes. In our experience, image quality is somewhat impaired with smallcalibre endoscopes of both generations when secretions and
TABLE 2

Results of patient satisfaction questionnaires for transnasal esophagogastroduodenoscopy

\begin{tabular}{lcc}
\hline Variable & Mean score & Range \\
\hline Acceptability & 6.6 & $1-10$ \\
Choking sensation & 1.8 & $1-10$ \\
Nasal discomfort & 1.7 & $0-10$ \\
Sore throat & 0.8 & $0-9$ \\
Abdominal discomfort & 1.1 & $0-10$ \\
\hline
\end{tabular}

All variables were assessed by scores between 0 and 10, with 10 indicating the most severe degree of each variable

bubbles are present due to poorer suction, lavage and air sufflation. However, several studies have reported that the rates of completion of the examination to the second part of the duodenum are high $(13,15)$, as was shown in the present study. The histological results with the small-calibre endoscopes using pediatric biopsy forceps (cup diameter of $1.8 \mathrm{~mm}$ compared with the $2.2 \mathrm{~mm}$ cup diameter of conventional forceps), through their $2 \mathrm{~mm}$ channels have been reported in some studies to be of good quality $(13,16)$ and even comparable to that of standard endosocopy (12). Saeian et al (17) showed in their prospective study that specimens obtained from conventional forceps and pediatric forceps were equivalent for providing documentation of Helicobacter pylori eradication with a rapid urease test. Whether the specimens provided by pediatric biopsy forceps are adequate in providing a diagnosis with equivalent accuracy to those obtained by the standard forceps needs to be further investigated.

Unsedated transnasal EGD can also be used in patients in whom per oral intubation is not possible (eg, tongue cancer and jaw fracture). Cirrhotic patients are at particular risk for developing prolonged hepatic encephalopathy following sedation. Unsedated transnasal EGD has been used in this patient group and was shown to be accurate in detecting and grading esophageal varices (18). Although transnasal EGD is not routinely used for therapeutic endoscopy, unsedated transnasal endoscopic placement of percutaneous endoscopic gastrostomy has already been reported $(19,20)$.

Although transnasal EGD appears to be a safe and effective alternative to conventional diagnostic EGD, it should be avoided in patients with coagulopathy and a history of nasal trauma or surgery. Conventional EGD is also more appropriate if there is a possible need for a therapeutic procedure or large biopsies.

\section{CONCLUSIONS}

Transnasal EGD is generally well tolerated, feasible and safe. It can be performed with topical anesthesia, without intravenous sedation in an outpatient setting. The low complication rate, high patient satisfaction and potential cost savings make transnasal endoscopy an attractive alternative to conventional EGD to screen patients for upper gastrointestinal tract diseases.

ACKNOWLEDGEMENTS: The authors thank Dr Gary May at the Centre for Therapeutic Endoscopy and Endoscopic Oncology, Division of Gastroenterology, St Michael's Hospital for reviewing the manuscript. 


\section{Cho et al}

\section{REFERENCES}

1. Silvis SE, Nebel O, Rogers G, Sugawa C, Mandelstom P. Endoscopic complications. Results of 1974 American Society for Gastrointestinal Endoscopy Survey. JAMA 1976;235:928-30.

2. Thompson DG, Lennard-Jones JE, Evans SJ, Cowan RE, Murray RS, Wright JT. Patients appreciate premedication for endoscopy. Lancet 1980;2:469-70.

3. Walker B, Smith MJ. Upper gastrointestinal endoscopy - a survey of patients' impressions. Postgrad Med J 1978;54:253-6.

4. Bell GD. Review article: Premedication and intravenous sedation for upper gastrointestinal endoscopy. Aliment Pharmacol Ther 1990;4:103-22.

5. Alcain G, Guillen P, Escolar A, Moreno M, Martin L. Predictive factors of oxygen desaturation during upper gastrointestinal endoscopy in nonsedated patients. Gastrointest Endosc 1998;48:143-7.

6. Muravchick S. Anesthesia for elderly patients. In: Barash PG, Cullen BF, Stoelting RK, eds. Clinical Anesthesia, 4th edn. Philadelphia: Lippincott Williams \& Wilkins, 2001:1205-16.

7. Mokhashi MS, Hawes RH. Struggling toward easier endoscopy. Gastrointest Endosc 1998;48:432-40.

8. Dean R, Dua K, Massey B, Berger W, Hogan WJ, Shaker R. A comparative study of unsedated transnasal esophagogastroduodenoscopy and conventional EGD. Gastrointest Endosc 1996;44:422-4.

9. Al-Atrakchi HA. Upper gastrointestinal endoscopy without sedation: A prospective study of 2000 examinations. Gastrointest Endosc 1989;35:79-81.

10. Froehlich F, Gonvers JJ, Fried M. Conscious sedation, clinically relevant complications and monitoring of endoscopy: Results of a nationwide survey in Switzerland. Endoscopy 1994;26:231-4.
11. Elfant AB, Scheider DM, Bourke MJ, et al. Prospective controlled trial of transnasal endoscopy (T-EGD) versus per-oral endoscopy (P-EGD). Gastrointest Endosc 1996;43:311. (Abst)

12. Dumortier J, Ponchon T, Scoazec JY, et al. Prospective evaluation of transnasal esophagogastroduodenoscopy: Feasibility and study on performance and tolerance. Gastrointest Endosc 1999;49:285-91.

13. Preiss C, Charton JP, Schumacher B, Neuhaus H. A Randomized trial of unsedated transnasal small-caliber esophagogastroduodenoscopy (EGD) versus peroral small-caliber EGD versus conventional EGD. Endoscopy 2003;35:641-6.

14. Dumortier J, Napoleon B, Hedelius F, et al. Unsedated transnasal EGD in daily practice: Results with 1100 consecutive patients. Gastrointest Endosc 2003;57:198-204.

15. Zaman A, Hahn M, Hapke R, Knigge K, Fennerty MB, Katon RM. A randomized trial of peroral versus transnasal unsedated endoscopy using an ultrathin videoendoscope. Gastrointet Endosc 1999;49:279-84.

16. Craig A, Hanlon J, Dent J, Schoeman M. A comparison of transnasal and transoral endoscopy with small-diameter endoscopes in unsedated patients. Gastrointest Endosc 1999;49:292-6.

17. Saeian K, Townsend WF, Rochling FA, et al. Unsedated transnasal EGD: An alternative approach to conventional esophagogastroduodenoscopy for documenting Helicobacter pylori eradication. Gastrointest Endosc 1999;49:297-301.

18. Saeian K, Staff D, Knox J, et al. Unsedated transnasal EGD: A new technique for accurately detecting and grading esophageal varices in cirrhotic patients. Am J Gastroenterol 2002;97:2246-9.

19. Taller A, Horvath E, Harsanyi L, Balatoni Z, Ilias L. Transnasal percutaneous endoscopic gastrostomy. Endoscopy 1997;29:337. (Lett)

20. Roman S, Pereira A, Caruso L, Sagnard P, Ponchon T, Dumortier J. [Transnasal percutaneous endoscopic gastrostomy.] Gastroenterol Clin Biol 2001;25:106-7. (Lett) 


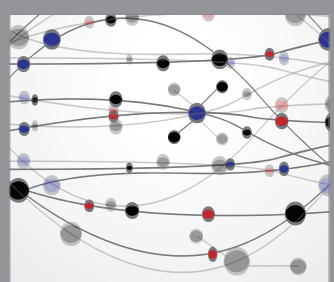

The Scientific World Journal
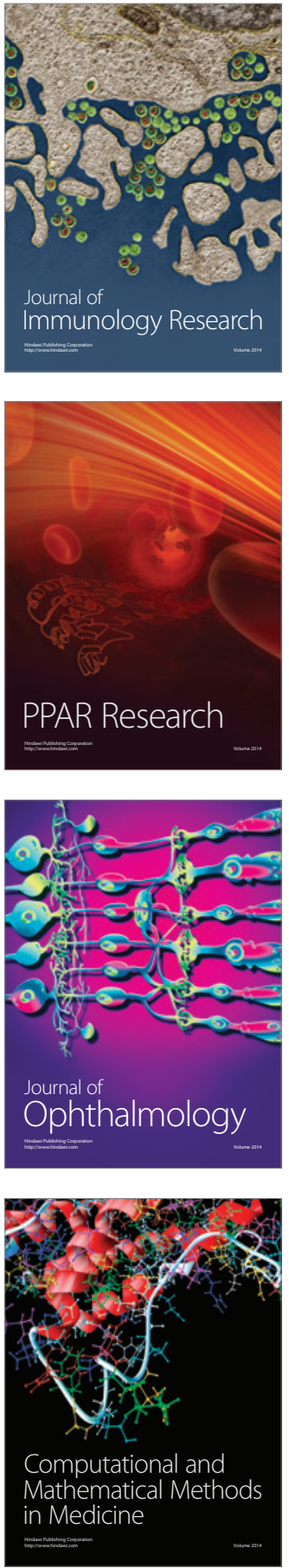

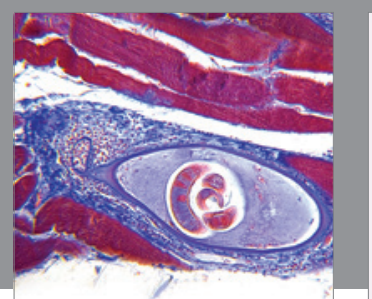

Gastroenterology Research and Practice

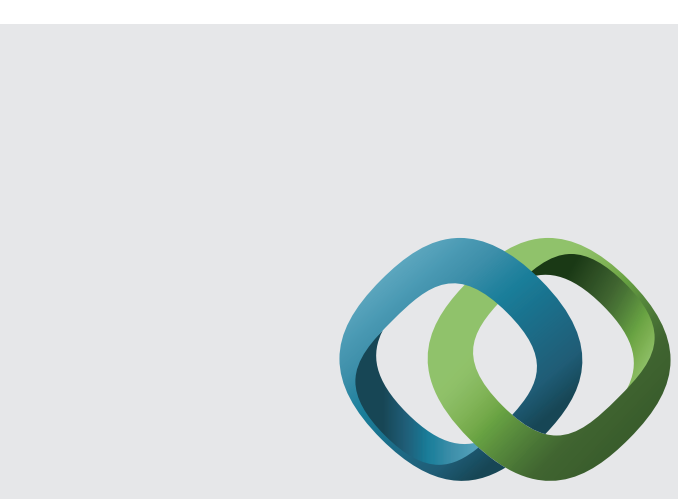

\section{Hindawi}

Submit your manuscripts at

http://www.hindawi.com
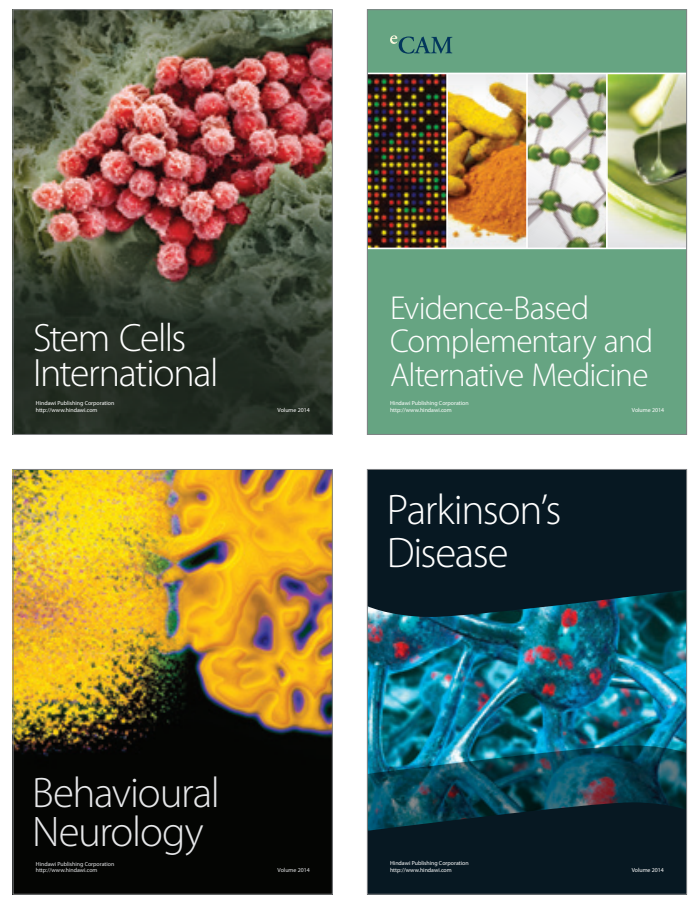
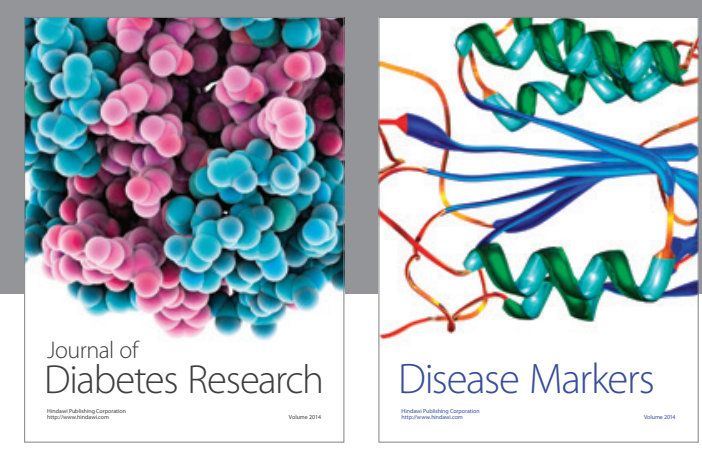

Disease Markers
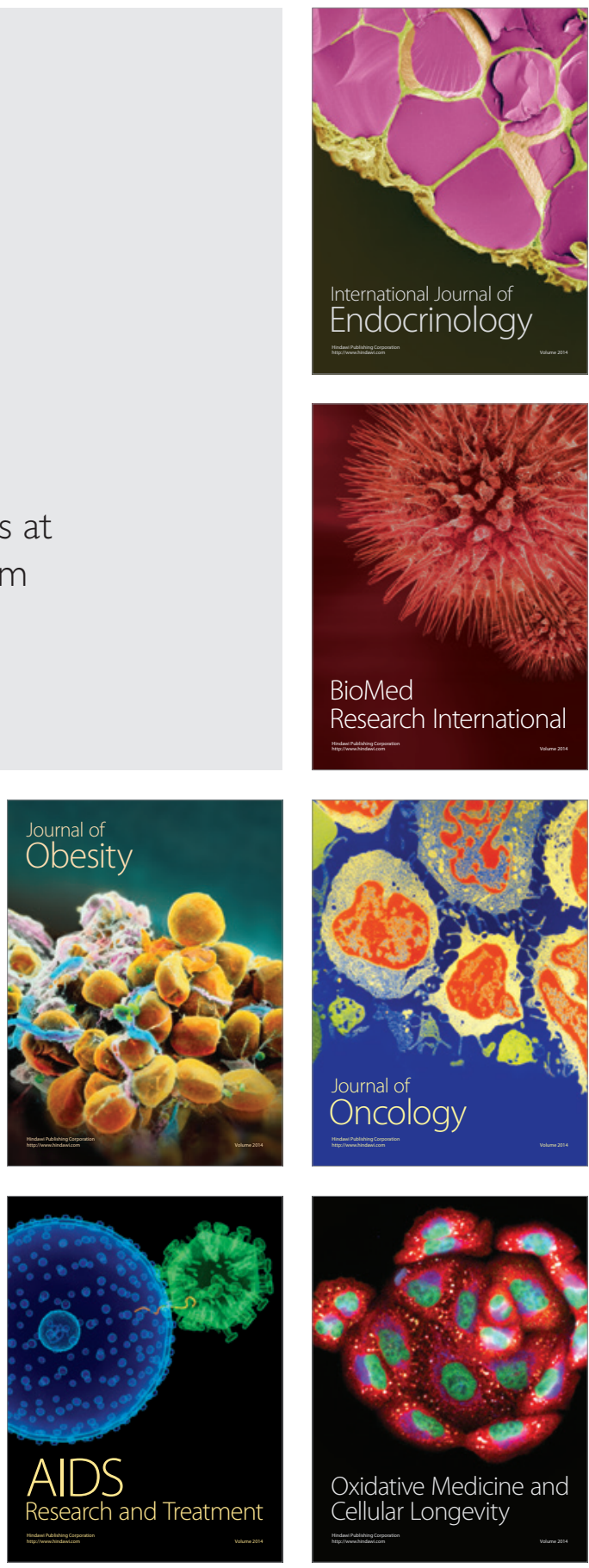